\title{
A severe complication of mid-urethral tapes solved by laparoscopic tape removal and ureterocutaneostomy
}

\author{
Tobias Schätz, MD; Stephan Hruby, MD; Daniela Colleselli, MD; Günter Janetschek, MD; Lukas Lusuardi, MD \\ Paracelsus Medical University Salzburg, Department of Urology and Andrology, Salzburg, Austria
}

Cite as: Can Urol Assoc J 2013;7(9-10):e598-600. http://dx.doi.org/10.5489/cuaj.393

Published online September 10, 2013.

\section{Abstract}

Mid-urethral tapes are largely used to manage stress urinary incontinence (SUI). In certain cases, however, this procedure results in bothersome complications that lead to complete resection. We present the case of an 85-year-old woman who presented with ongoing suprapubic pain, hematuria, vaginal bleeding and recurrent urinary tract infections. The patient had undergone a tensionfree vaginal tape (TVT) procedure in 1999 and a transobturator tape (TOT) placement in 2003 for SUI. Investigations revealed a urethral stone, erosion of both TOT and TVT and an urethra-vaginal fistula. Under local anesthesia the urethral stone was removed endoscopically and the TOT removed via a vaginal approach. Due to her comorbidity, she underwent a laparoscopic intraperitoneal removal of the TVT and a definitive ureterocutaneostomy to relieve her pain, inflammation and incontinence. This is the first ever presented case of erosion of mid-urethral tapes and incontinence treated with a laparoscopic resection of the tape and ureterocutaneostomy as definitive urinary diversion.

\section{Introduction}

The tension-free vaginal tape (TVT, Gynecare, Sommerville, NJ) was introduced in 1996. ${ }^{1}$ This technique has long-term efficacy similar to that of Burch colposuspension. ${ }^{2}$ Since then other retropubic and more recently transobturator tapes (TOT) have been introduced, making mid-urethral sling procedures less invasive and safer. ${ }^{3,4}$

Complications after these procedures are perceived to be rare. The cumulative complications rates were $0.8 \%$ for bladder erosion, $1.1 \%$ for vaginal erosion, $1.7 \%$ for pelvic hematoma, $3.2 \%$ for revision operations, $3.4 \%$ for bladder perforations, $4 \%$ for clean intermittent catheterization, $9.7 \%$ for urinary tract infections, $15.6 \%$ for storage lower urinary tract symptoms (LUTS) and $16.1 \%$ for voiding LUTS. ${ }^{3}$ Catastrophic complications, such as major hemorrhage from large vessels or bowel perforation, usually become apparent intra- or immediately after surgery. We present a case of a catastrophic complication presenting years after tape insertion.

\section{Case report}

In April 2010, an 85-year-old woman presented with perineal pain, continuous incontinence and offensive smelling urine. She had a history of TVT in 1999 for stress urinary incontinence (SUI) and a TOT in 2003 for persistent SUI elsewhere. Her general medical condition was poor. She had several pulmonary infarcts and currently was suffering from angina with an exercise tolerance of 100 metres.

Urine culture was positive for $\mathrm{E}$. coli. A local anesthetic rigid cystoscopy revealed a small mid-urethral stone adherent to an eroded tape in the 6-o'clock position. There was further erosion at the bladder neck at the 1-o'clock position. Vaginal examination revealed the presence of a urethravaginal fistula.

The urethral stone was totally removed with cold cup biopsy forceps and the underlying tape was divided and partially removed. There was an unsuccessful attempt to remove the eroded tape from the lateral sides of the bladder neck and a suprapubic catheter was inserted. Cystography confirmed the urethro-vaginal fistula without other abnormalities.

Postoperatively, the patient developed pain and swelling of the mons pubis. She had no inflammatory signs or elevated serum inflammatory markers. A computed tomography scan showed a 6 -cm fluid collection at the mons pubis connected to inflammation within the retropubic space (Fig. 1). In addition, the impression of the TVT could be seen as a V-shaped soft tissue density surrounded by further inflammation. 


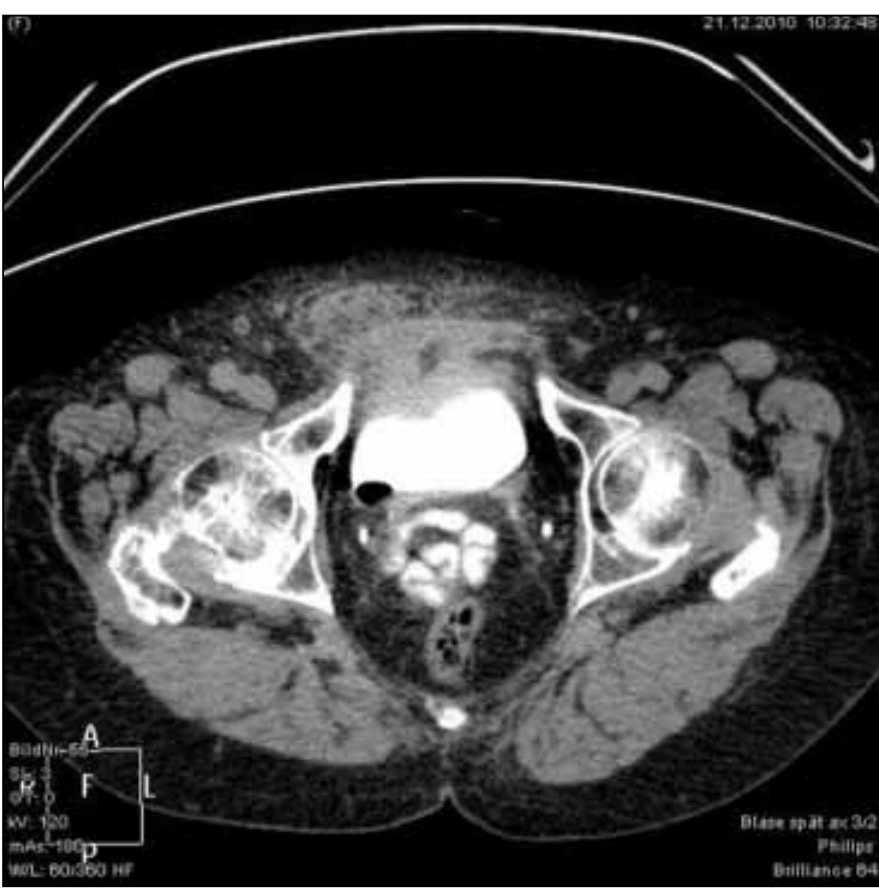

Fig. 1. A computed tomography scan showing a $6-\mathrm{cm}$ fluid collection at the mons pubis connected to inflammation within the retropubic space.

Unfortunately the patient was still incontinent and in pain. In view of her comorbidity (ASA IV) and the absence of sepsis, the decision was taken to remove the tape and perform bilateral uretrocutaneostomy using minimally invasive techniques.

A transperitoneal laparoscopic approach was employed. The retropubic space was opened and the bladder dropped posteriorly. The pubic bone was identified laterally and followed the midline. By this movement the limbs of the TVT on either side could be identified and removed (Fig. 2). We mobilized the distal ureters bilaterally and transected them. The left ureter was tunneled through the sigmoid mesentery and both ureters were brought to the skin of the right iliac fossa.

\section{Discussion}

Vaginal erosion is a rare complication of TOT with a reported incidence of $0 \%$ to $1.5 \% .^{3}$ Erosion secondary to TVT is more common with an incidence of $0 \%$ to $10.9 \%{ }^{3,5}$ In our case we had an erosion of both mid-urethral tapes. To our knowledge this is the first report of complications following both TVT and TOT used concurrently in the same patient. The value of a repeat midurethral sling after a failed primary sling is not generally accepted, ${ }^{6,7}$ but the management of recurrent or persistent SUI after previous mid-urethral sling remains a challenge for the practicing gynecologist and urologist. Potentially, these patients could be treated with bulking agents, abdominal or laparoscopic urethropexy,

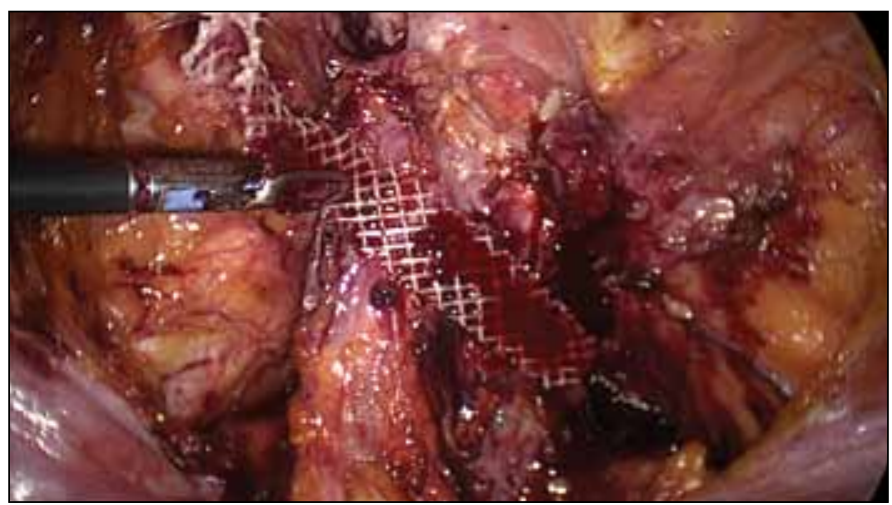

Fig. 2. Laparoscopic removal of the tension-free vaginal tape.

artificial urethral sphincter, and repeat mid-urethral sling. ${ }^{6,7}$

While it is now clinically justified to employ a second tape without removing a failed tape, ${ }^{6,7}$ we were driven to intervene given the clinical situation that faced us.

Several ways to manage erosion have been described from no treatment, conservative local management to complete resection with endoscopy or open surgery. ${ }^{8,9}$ In our case we had an unfit, elderly woman with erosion of both tapes into the urethra and the TOT into the vagina with continuous complete incontinence. We therefore needed a solution that was minimally invasive and provided definitive resolution of her incontinence.

There are only 3 reports describing laparoscopic resection of mid-urethral tapes, ${ }^{8-10}$ and there are only few reports describing laparoscopic ureterocutaneostomy. ${ }^{11,12,13} \mathrm{We}$ combined these two techniques to provide relief from pain, inflammation and incontinence.

\section{Conclusion}

We do not believe that the concomitant use of two different mid-urethral tapes can be clinically justified. This may have led to the severe case of erosion and fistula without improved continence. Laparoscopic surgery to remove the tape was safe and efficacious in this unfortunate scenario. Laparoscopy can also provide an effective solution for incontinence in an elderly, comorbid patient.

Competing interests: None declared.

This paper has been peer-reviewed.

\section{References}

1. Ulmsten U, Petros P. Intravaginal slingplasty (IVS): an ambulatory surgical procedure for treatment of female urinary incontinence. Scand J Urol Nephrol 1995;29:75-82. http://dx.doi. org/10.3109/00365599509180543 
Schätz et al.

2. McCracken GR, Henderson NA, Ashe RG. Five year follow-up comparing tension-free vaginal tape and colposuspension. Ulster Med J 2007;76:146-9.

3. Novara $G$, Galfano A, Boscolo-Berto R, et al. Complication rates of tension-free midurethral slings in the treatment of female stress urinary incontinence: a systematic review and meta-analysis of randomized controlled trials comparing tension-free midurethral tapes to other surgical procedures and different devices. Eur Urol 2008;53:288-308. http://dx.doi.org/10.1016/i.eururo.2007.10.073

4. Delorme E. Transobturator urethral suspension: mini-invasive procedure in the treatment of stress urinary incontinence in women. Prog Urol 2001;11:1306-13.

5. Novara G, Artibani W, Barber MD, et al. Updated systematic review and meta-analysis of the comparative data on colposuspensions, pubovaginal slings, and midurethral tapes in the surgical treatment of female stress urinary incontinence. Eur Urol 2010;58:218-38. http://dx.doi.org/10.1016/i. eururo.2010.04.022

6. Verbrugghe A, De Ridder D, Van der Aa F. A repeat mid-urethral sling as valuable treatment for persistent or recurrent stress urinary incontinence. Int Urogynecol J 2013;24:999-1004. http://dx.doi.org/10.1007/ s00192-012-1971-0. Epub 2012 Oct 24.

7. Parden AM, Gleason JL, Jauk $V$, et al. Incontinence outcomes in women undergoing primary and repeat midurethral sling procedures. Obstet Gynecol 2013;121: 273-8.

8. Pikaart DP, Miklos JR, Moore RD. Laparoscopic removal of pubovaginal polypropylene tension-free tape slings. JSLS 2006;10:220-5
9. Rouprêt M, Misraï V, Vaessen C, et al. Laparoscopic surgical complete sling resection for tension-free vaginal tape-related complications refractory to first-line conservative management: a single-centre experience. Eur Urol 2010;58:270-4. http://dx.doi.org/10.1016/i.eururo.2010.04.025

10. Rigaud J, Pothin P, Labat JJ, et al. Functional results after tape removal for chronic pelvic pain following tension-free vaginal tape or transobturator tape. J Urol 2010;184:610-5. http://dx.doi.org/10.1016/i. juro.2010.03.132

11. Rassweiler JJ, Seemann 0, Frede T, et al. Retroperitoneoscopy: experience with 200 cases. J Urol 1998;160:1265-9. http://dx.doi.org/10.1016/S0022-5347(01)62512-6

12. Nakamura E, Terachi T, Kamoto $\mathrm{T}$, et al. Retroperitoneoscopic ureterocutaneostomy for obstructive uropathy with advanced bladder cancer: a case report. Int J Urol 2002;9:60-2. http://dx.doi.org/10.1046/ j. $1442-2042.2002 .00420 . x$

13. Metzelder $M$, Petersen C, Ure B. Laparoscopic ureterocutaneostomy for urinary diversion in selected infants. Eur J Pediatr Surg 2008;18:86-8. http://dx.doi.org/10.1055/s-2007-989297

Correspondence: Dr. Tobias Schätz, Paracelsus Medical University Salzburg, Department of Urology and Andrology, Müllner Hauptstr. 48, 5020 Salzburg, Austria; fax: +43 6624482 2971; to.schaetz@salk.at 